\title{
What's the Problem Now?
}

\author{
Randall Bass
}

\begin{abstract}
Revisiting an essay from 1999, this article explores the current conditions in higher education, and society more broadly, that help shape the roles for the scholarship of teaching and learning (SoTL) and educational development. By seeing the current "crises" of higher education not only as "problems" to be investigated but as a "wicked problem," we might be able to elevate and complicate the role that inquiry into teaching and learning might play in institutional change and the expansion of higher education. The article argues for the necessity, even urgency, of seeing educational development as a lever for change, fully engaged with the most important questions surrounding the role of higher education in shaping the future.
\end{abstract}

Keywords: scholarship of teaching and learning, organizational change, innovation, educational development, professional learning, higher education, equity and inclusion

But then, you may agree that it becomes morally objectionable for the planner to treat a wicked problem as though it were a tame one, or to tame a wicked problem prematurely, or to refuse to recognize the inherent wickedness of social problems.

- Horst W. J. Rittel and Melvin M. Webber, "Dilemmas in a General Theory of Planning" (1973) 
On the evening of October 30, 2018, I was preparing to travel to Carnegie Mellon University to keynote their annual Teaching \& Learning Summit, when I remembered that I was flying to Pittsburgh. That was significant because just three days before a horrific shooting had taken place in a Jewish synagogue, in a neighborhood essentially adjacent both to Carnegie Mellon and the University of Pittsburgh.

I stopped what I was doing and logged onto the website of Carnegie Mellon's Eberly Center, one of the great centers for teaching and learning in the United States, to see how they were responding to the incident. The top resource was titled, "Teaching After Tragedy," with the descriptor, "As an instructor, it's important to consider the impacts such events have on students as human beings and learners. What can instructors do to support students in the wake of tragedy or crisis, regardless of what they are teaching in their courses?" (Eberly Center, n.d.).

I know such rapid responses by a teaching center are all too familiar by now. Yet, this felt like a marker to me. It seemed like both a pointed response to a horrific incident of profound and shattering proximity and an eerily normalized response of a center for teaching and learning whose core business, by definition, is matching pedagogical practice to instructional needs. It just so happened that this week's instructional needs were coping with hate, bigotry, violence, and loss.

When I was invited by the editors of To Improve the Academy to write something for the 20-year anniversary of an essay I published in 1999 titled "The Scholarship of Teaching and Learning: What's the Problem?" (Bass, 1999), the first title that came to mind was, "What's the Problem Now?" It is impossible to think about the task of this article-and about the meaning of now — without thinking about that collision between a tragic event and a center for teaching and learning and about so many others like them. I think about all of the practices in centers for teaching and learning, carried out by educators and educational developers, whose devotion to the advancement of learning unfolds in the context of local and world events, social discourse, and even the existential threats of the coming decades. 
I don't know why the Pittsburgh moment had such an impact on me. Perhaps it was the normalized nature of it, that this was now part of the business of educational development. Or, perhaps, it was something more existential. There was something profoundly asymmetrical about the conjunction of a hate crime/mass shooting and classroom pedagogy. And that asymmetry speaks to the nature of the problem of learning in 2020.

This article then is an update on that 1999 essay, its ideas and contexts, with the sole purpose of offering a provocation for how we understand the role of the scholarship of teaching and learning (SoTL) and, more broadly, educational development in our current moment. My purpose here is not so much to theorize on the nature or practices of educational development as a field, nor on the relationship of SoTL to educational development. Many others are engaged in that work, including in the pages of this journal. My focus here is primarily one of speculation and questioning, to explore the contours of how we now think about the problem of learning and the implications of that for practice.

Irrespective of how one conceptualizes it, SoTL has become part of a much broader investigative and formational toolkit that comprises the field of educational development. And the field of educational development, as heterogeneous as its contexts and practices are, is becoming ever more relevant and connected to the ways that education serves society, from equity and mobility, to the shifting demands of disciplinary and interdisciplinary competence, to the "robotproofing" of graduates for a flourishing human future. The framework for appreciating SoTL at the time of my original essay, as a way for teachers to understand their students' learning as a rich field of investigation, has expanded in the last 20 years as a robust, diverse, and potentially transformative portfolio of tools and practices, the richness of which matches the urgency of the times. What are we to make of this convergence of knowledge, tools, and urgency? What might the next phase of educational development and professional learning in higher education look like, if we were to follow the trajectory of the last 20 years?

To Improve the Academy • Vol. 39, No. 1 • Spring 2020 
In short, my argument is this: We need to think of the problem of learning - and by implication, the problem of higher education-as a complex, wicked problem. As a working definition, "A wicked problem is a social or cultural problem that is difficult or impossible to solve for as many as four reasons: incomplete or contradictory knowledge, the number of people and opinions involved, the large economic burden, and the interconnected nature of these problems with other problems" (Austin Center for Design, 2019). The concept of wicked problems has become an important one to planners and problemsolvers because it fundamentally reframes the work of approaching a complex, high-stakes problem. I argue that seeing learning and education as a wicked problem, rather than a tame or solvable one, is a comparable "problem turn" to the one 20 years ago that elevated teaching and learning as a focus of serious inquiry. With this problem turn, I engage the question, "What's the problem now?" as an invitation to think more broadly and ambitiously about the role of educational development in the reconfiguration of higher education and the role of education in the broader learning ecosystem.

\section{What Was the Problem Then?}

"The Scholarship of Teaching and Learning: What's the Problem?" is an exploration of the emerging idea of the SoTL movement in the 1990 s that we could take teaching and learning seriously as an area of inquiry. That is, it was not only that teaching as a category of professional activity is as valuable as research but also that inquiry into teaching could be valued as research. Valued in this way, one could view teaching, generatively, as a source of problems to be investigated (as in research) as opposed to problems to be fixed, as we tend to associate with problems in teaching.

In this context, the essay was a personal exploration of my own teaching in which I encountered a personal crisis in my pedagogy (and teaching evaluations, pre-tenure) and how-using the ethos and meth- 
odology of SoTL-turned the crisis into a set of intellectual problems to be investigated. As a professor of literature, highly influenced by the broader SoTL movement, I began to ask deeper questions about how my students developed a complex understanding of literature and culture, how they approached the material, how they engaged in acts of reading and rereading as foundational to the kinds of intellectual work and outcomes I hoped for them. The SoTL movement gave me three kinds of supports to ask those questions and enabled me to reframe a teaching problem as a learning inquiry problem:

1. a stance toward my students' learning that understood it to be complex and nuanced;

2. tools of inquiry that gave me a process and a practice; and

3. a community for the work, which meant more than just knowing there was an audience but that by definition a community meant that there was a knowledge base to build on and something important at stake that was shared by many and to which my focused work could contribute.

My 20-year journey since then led me from studying my own classroom practice to founding and directing, for 13 years, a comprehensive center for teaching and learning that was deeply informed by SoTL, then onto a position as vice provost for education leading a "curriculum incubator" aimed at institutional change. In essence, my journey was from individual practice to a community of educators who cared about teaching and learning, to systems thinking about the university. Each phase gave me perspective on the nested nature of these scales: individual pedagogy is always embedded in a community. And a community is shaped by the systems (institutions, structures, policies, culture) that make it possible and define its existence. These systems of course are embedded in a wider ecosystem shaped by social and economic forces. This is the situation (i.e., the layered, situated nature) of the problem of learning now.

My journey follows in some ways the educational development 
movement that has fully developed in the same period. Just as there has been a shift in educational development from individual to systems (Gibbs, 2013), the problem in my teaching becomes the problems of higher education and the role of education. Just as SoTL gave me a stance and tools to engage my own teaching issues as problems to be investigated, might we think similarly about the stance, ethos, and tools of educational development to turn the issues and problems facing higher education into a massive and concerted program of inquiry that takes as its research program the full portfolio of challenges facing higher education and our society?

What could it mean to turn the current crises and challenges of higher education into a set of problems to be investigated? And if we did, what kind of a problem should we consider it to be? How might the role of educational developers, and educators more broadly, contribute to a substantial and widely distributed inquiry into the improvement and expansion of higher education to meet the needs of society, equity, and the future? Such a problem turn in higher education would require a reframing, seeing the problem of learning and education in fresh ways, as complexly embedded in social and cultural contexts, webs of interdependencies, and new intellectual tools. Just as my problem turn 20 years ago empowered me to look at my students' learning in a whole new way, this problem turn should be equally empowering to educational developers, researchers, and practitioners in the new learning ecosystem.

\section{What Kind of Problem Is the Problem of Learning Now?}

By calling this article "What's the Problem Now?" I want to call attention to the force of "now" in the sense that Martin Luther King Jr. invoked it in the "fierce urgency of now": "We are now faced with the fact that tomorrow is today. We are confronted with the fierce urgency of now. In this unfolding conundrum of life and history, there "is" such a thing as being too late" (King, 1967a). 
Gomez (2017) notes that the phrase "the fierce urgency of now has, understandably, made its way into our education reform vocabulary" and that "most interpret the phrase ... as urging that schools, teachers, researchers, policymakers, and others need to stop dithering and wasting time, and get down to the business of eradicating unacceptable educational problems with all deliberate speed." But this sense of urgency is only one of the valences of the phrase, as it has a broader meaning for King in that it points to the larger systemic conditions that situate the urgency.

As Gomez (2017) puts it, "In his urging society at that time to fiercely concentrate and focus on the palpable challenges to humanity, Dr. King also signaled the importance of another essential form of vigilance-attention to systems and contexts." For King, no issue was just about that issue: education is about poverty, poverty is about race, and "the problem of racism, the problem of economic exploitation, and the problem of war are all tied together" (King, 1967b). Similarly, no local struggle is ever purely local but connected to a broader interconnected global struggle.

On this point, Gomez (2017) points out that in King's "fierce urgency of now," there is a "duality of proper attention" in which "fast deliberate action must be coupled to thoughtful analysis and appreciation of systemic context." This then is the particular nexus of the higher education problem that I want to explore. I want to invoke this sense of "now" to raise not only the urgency behind the problems driving the work of educational developers but also the particular kinds of applied contexts in which they must be explored. If we are to use the qualities of the "now" to take teaching and learning seriously as well as to make that seriousness an urgent, if not moral, imperative, then we have to ask: What kind of a problem is the problem of learning? How complexly we understand the problem of learning and education will shape the next urgent phase of transformation in higher education. King would have a clear answer to the question posed by Rittel and Webber (1973) in the epigraph to this article: it is morally objectionable to misunderstand a wicked problem for a tame one. 
To build this point, I want to begin by arguing that the problem of learning in higher education is really a complex interplay of three related problems:

1. We have the problem of better understanding human learning. This is a profoundly interdisciplinary problem.

2. We have the problem of applying our understanding of learning to scaling and sustaining quality education to everyone, equitably. This is a complex problem with many dimensions.

3. Finally, we have the long-term problem of reimagining and enacting education so that it plays a meaningful role in creating a more just society and fostering a sustainable human future. This problem reframes the first two and makes the whole set, together, a wicked problem.

Let's reflect on this list for a moment. Typically, I believe, the purview of most faculty and educational developers is problem \#2, drawing increasingly and effectively on the findings of problem \#1. Of course, the principles of SoTL, and increasingly all educational development, are also about the dynamic relationship of \#1 and \#2, as more of the community grapples with the interplay of "theory with practical application" and the need to "place science in conversation with recent educational research and actual classroom practices" (Eyler, 2018 , p. 13). However, I don't think that problem \#3, education's impact on a human future, has had much of an impact yet on the transformation in higher education, despite the steady stream of abstract arguments about citizenship, civility, and flourishing, along with excellent (though largely still marginal) work in areas such as civic engagement and well-being.

Each of these problems is deeply interdependent with the others, in that they each get at different levels of educational practice and the impact that education might have on the future in different ways. Each of these problems exerts pressure on the others to constitute the distinctive kind of problem that the problem of learning and education 
poses. And this point I especially want to emphasize: taken together, the problem of learning becomes far more complex than it is typically regarded, especially as it relates to higher education. While problems $\# 1$ and \#2, by themselves, are pretty complex, certainly, all three of these problems together-their full complexity and extensibilityconstitute the wicked problem of education and human learning.

In every research field, there is a deep and dynamic relationship between a field's growing knowledge, frameworks, and tools, on the one hand, and the size, scope and ambition of the questions being asked, on the other. By understanding the problem of learning as a wicked problem, I am merely suggesting that the co-evolution of the field's problems and the tools it has to address them should radically expand our approaches toward improving education rather than narrow them.

\section{The Problem of Learning as a Wicked Problem}

As a complex problem, higher education tends to get viewed by society as a flawed or broken system in need of fixing, rather than as a "grand challenge." What would be different if we considered education, higher education, and, more broadly, human learning as a wicked problem and a grand challenge to be addressed rather than a problem to be fixed? Thinking of higher education as broken presupposes a problem in a search for narrow solutions that merely need to be applied rather than seeing education itself as a complex subject of inquiry requiring thoughtful responses. How many of Audrey Watters's (2019) "100 Worst Ed-Tech Debacles of the Decade" were the result of a way of thinking about higher education as a tame and solvable problem?

Upgrading our sense of the problem of learning to a wicked problem is a way of honoring the complexity and urgency of the questions facing us. At minimum, then, it would mean taking as a starting premise that the problem of learning has many interdependent complexi- 
ties and a dynamic set of questions requiring extensive, ambitious, and unrelenting interdisciplinary investigation, innovation, and imagination, as all wicked problems demand. Indeed, this is an era when universities are increasingly turning to grand challenge strategies, organizing themselves in new ways in order to deploy resources across their "silos" to take on the most complex global issues and challenges (Weiss and Khademian, 2019). Yet, nearly none of these grand challenges ever turn to the university's own core practices and its larger context. Why shouldn't the advance of human learning and education's role in shaping a more just society be considered a grand challenge? (note that "Advance Personalized Learning" is one of the engineering grand challenges; NAE, 2019).

Rittel and Webber (1973) argue that "societal problems are inherently different from the problems that scientists and perhaps some classes of engineers deal with. Planning problems are inherently wicked" (p. 160). They develop the idea of wicked problems through 10 distinguishing properties, six of which are particularly pertinent here:

- There is no definitive formulation of a wicked problem.

- Wicked problems have no stopping rule.

- There is no immediate and no ultimate test of a solution to a wicked problem.

- Wicked problems do not have an enumerable (or an exhaustively describable) set of potential solutions, nor is there a well-described set of permissible operations that may be incorporated into the plan.

- Every wicked problem is essentially unique.

- Every wicked problem can be considered to be a symptom of another problem. (Rittel \& Webber, 1973, pp. 161-165)

To be clear: seeing the problem of learning and higher education as a wicked problem does not mean that we cannot be continuously establishing, testing, and promoting best practices that have high levels of certainty for their impact. Every wicked problem has bounded 
problems that are constitutive of the larger one and are addressable. Consider, for example, the fantastic work across the country around "student success," whether at the level of classroom practice, integration of services across academic and student affairs, or the use of equity-minded data to provoke change and institutional transformation. Yet if one understands the problem of student success as a tame problem, it is likely we will focus only on strategies intended to have direct impact on student learning, persistence, and completion. If student success is seen as a wicked problem, then the "equity agenda" is less likely to be compartmentalized as the problem of one division of campus or seen as something to consider separate from faculty culture or distinct from how inequities are hard-wired into many of the institution's core practices and opportunities, let alone larger connections to socioeconomic inequality, polarization, and systemic racism.

To open this up a bit further, let's look at a recent issue of Daedalus (fall 2019), edited by Sandy Baum and Michael McPherson on behalf of the American Academy of Arts and Sciences. The entire issue is dedicated to "Improving Teaching: Strengthening the College Learning Experience." As a project of the Commission on the Future of Undergraduate Education, it is intended to be a follow-up to the national report, "The Future of Undergraduate Education, the Future of America." The premise for the project and the volume is that we can improve student learning by improving teaching. That this idea itself seems to be a stubborn, persistent, and multi-dimensional problem is probably testament enough to the complexity and intractability of the problem of scaling quality education equitably (problem \#2).

Yet the focus on improving college teaching invokes a complicated web of tangled topics, including, to name only some: the dependence of improving undergraduate STEM education on academic change management strategies; the interplay of disciplinary and teaching expertise in advancing research-based practices; the challenges of race and racism, democracy, and civic education in building capacity in students through critical learning experiences; the false dichotomy of academic learning and occupational skills in educating a resilient work- 
force; the role of higher education funding and socioeconomic inequality in shaping differential student outcomes in the unequal tiers of the higher education system; and the durability and adaptability of a liberal arts education in the face of automation and the failure of online learning to live up to the promise of serving the underserved, in large part because of the particular needs of this population for strategies that require "considerable skilled human interaction."

For all this complexity, every one of these tangled topics opens out into adjacencies that are all equally as important to the future of human learning. The very complexity and embedded nature of the challenge of improving college teaching in order to improve student learning is evidence of its wickedness as a problem. Yet most discourse, outside and often inside the institution, will represent this intractability as a pathology of a broken system (tenure, privilege, turf protection, whatever) and not the consequence of complex competing aims, missions, and values and the relatively recent problem of needing to scale an inherently difficult-to-scale endeavor (i.e., quality education) and to do so democratically and equitably.

What the volume's tangle of issues suggests is the growing sense in the discourse on improving higher education that no issue of learning is ever just about pedagogical practice, technique, or the simple application of evidence-based approaches. Any serious address of improving teaching, deeply and long term, will require the kind of understanding and action that can only come from shifting how we take on the problem of learning as a problem-and at every level of scale, from high-level learning research to educational development in a local institutional setting.

\section{Convergence Research and the Problem of Learning}

This suggests that we don't just need new approaches; we need new approaches to developing new approaches. Large-scale research programs in many sectors that are focused on grand challenges and 
wicked problems are not only interdisciplinary in their methods and perspectives but intensively collaborative in their address. The extreme version of this is what the National Science Foundation (NSF) calls "Convergence research," and it is one of their 10 big ideas for investments in the future.

Convergence research is a means of solving vexing research problems, in particular, complex problems focusing on societal needs. It entails integrating knowledge, methods, and expertise from different disciplines and forming novel frameworks to catalyze scientific discovery and innovation. Convergence research is related to other forms of research that span disciplines-transdisciplinarity, interdisciplinarity, and multidisciplinarity. It is the closest to transdisciplinary research which was historically viewed as the pinnacle of evolutionary integration across disciplines. (NSF, 2019)

The NSF identifies Convergence research as having two primary characteristics:

1. Research driven by a specific and compelling problem. Convergence Research is generally inspired by the need to address a specific challenge or opportunity, whether it arises from deep scientific questions or pressing societal needs.

2. Deep integration across disciplines. As experts from different disciplines pursue common research challenges, their knowledge, theories, methods, data, research communities, and languages become increasingly intermingled or integrated. New frameworks, paradigms or even disciplines can form sustained interactions across multiple communities. (NSF, 2019)

Convergence research has been a concept in play for almost a decade, though its application has deepened in recent years. The report Convergence: The Future of Health (2016) asserts that "the Convergence Revolution holds the potential to address the most sig- 
nificant challenges of human existence in the 21st century" (p. 19). Crucially, "the Convergence Revolution does not rest on a particular scientific advance but on a new integrated approach for achieving advances" (p. 17).

While Convergence and interdisciplinary research are closely allied, Convergence is different because it goes beyond collaboration: Convergence is the integration of historically distinct disciplines and technologies into a unified whole that creates fundamentally new opportunities for life science and medical practice. (p. 17)

In many ways, Convergence research in the "future of health" is a good analogy for education because of the particular relationship of research with practice, which, in medicine and education, is both the context for research itself and the beneficiary of findings. John Dewey makes this point when he says that educational practice is "'the beginning and the close' of all educational inquiry," as it is "the final test of value of the conclusions of all researches" (qtd. in Biesta \& Burbules, 2004, p. 79). What would Convergence research look like as applied to education and, in particular, higher education, where educational practice was the ultimate target of such research? The question has bearing not only on the kind of problem or problems that we have but on the particular nature of education as a problem and how institutions and the sector are organized to adapt and evolve. Part of the "Convergence Revolution" has not merely been new ways for disciplines to collaborate but changes in how the research community is even organized, "such as university structure, nature of interdisciplinary research, and support for collaboration in teams" (Convergence, 2016, p. 8).

Similarly, we might imagine that a Convergence approach to research in higher education would be similarly transdisciplinary, interdisciplinary, and multidisciplinary, combining disciplines as different as the learning sciences, critical race theory, well-being, design, technology, innovation, sustainability, learning systems, data 
analytics, artificial intelligence and machine learning, storytelling and cultural performance, imagination, human ecology, human relationships, developmental psychology, strategy, organization and institutional change, and more. Yet it is not just the transdisciplinary or interdisciplinary nature that would distinguish what Convergence research might look like in higher education, but the diverse configurations of how knowledge gets created and shared would as well. Convergence research in higher education would span applied theory, educational research, data analytics, SoTL, evidence-based practices, institutional learning, change management, experimental learning designs, inquiry by way of entrepreneurial ventures, and the dynamics of organizational cultures (institutions, systems, startups, community organizations, learning services, vendors) across the entire learning ecosystem.

Although we are far from where medicine is, where Convergence could lead to "the integration of historically distinct disciplines and technologies into a unified whole," we can at least privilege movement toward Convergence rather than its opposite. I'm concerned that the range of fields and subfields above will be increasingly driven by specialization, the quest for legitimacy, and the competition for funding such that the field of learning research and educational development will become increasingly fractured, speaking their own languages, attending their own meetings and circulating their increasingly specialized literatures.

To imagine a Convergence research approach to learning and higher education, we would need to push on our own boundaries; conceptualize the higher education ecosystem with an eye to its diversity and complexity; and engage theories, frameworks, and practices in ways consistent with the address of a wicked problem. At the same time, we need new frameworks by which to bring diverse specializations together to engage new understandings. Part of this will look like new field formations that are seeking a more convergent approach. This is what Cottom (2019) suggests in proposing a newly interdisciplinary field of "sociology of Edtech," which she proposes "can call us 
from our academic tracks and our learning centers-from our respective silos-and join us as a community of practice to think about the messy, multidimensional whole" (p. 22). Similarly, Kim and Maloney (2020) suggest that we need to recognize what they call "learning innovation" as a field. In their formulation, the field of learning innovation studies the relationship of the application of the learning sciences to the transformation of institutions, arguing that

We do not have a comprehensive understanding of how theories of design, technology, innovation, and analytics are challenging our fundamental assumptions about teaching and learning in higher education. These are the central questions of what we are calling "learning innovation." (p. 6)

Both sociology of edtech and learning innovation are important and telling early gestures toward a Convergence approach.

There are many implications for this turn, for institutions, foundations, venture funders, state systems, professional networks, and so forth, too many to take on here. But in my final section, I reflect on how this reframed view of the problem of learning as a wicked problem and the adaptation of a Convergence research approach to education might have impact on the field and the work that educational developers do.

\section{A Call to Action: The Multiple Ecologies of Educational Development}

Education is a thoroughly human practice in which questions about "how" are inseparable from questions about "why" and "what for."

-Gert J. J. Biesta and Nicholas C. Burbules, Pragmatism and Educational Research (2004)

At the beginning of this article I said that there was something "profoundly asymmetrical about the conjunction of a hate crime/mass 
shooting and classroom pedagogy" and that "that asymmetry speaks to the nature of the problem of learning in 2020." The asymmetry is a window onto the wicked nature of the problem. The classroom is connected to the larger world, whether it is responding to the world as it erupts and intrudes, prepping the next generation of problem-solvers to handle the most existential challenges, or seeking to realize the promise of higher education to speak to our higher values. Yet we often treat the problem of learning in bounded isolation in the context of learning design, learning goals, outcomes, and assessment of institutional effectiveness.

Educational developers should be active, imaginative, and capable "principal investigators" of the asymmetry between the classroom and the world. By that I mean that the people whose role it is to promote quality learning, innovation, and transformation in higher education should take the wickedness and urgency of the problem of learning as the defining core of their work. Of course, we need leadership at every level to do the same. But I believe that educational developers, learning designers, and educational innovators are in a unique and important position to frame the problem of learning for other stakeholders in education.

Work in the sector already embodies this in many ways, especially around issues of diversity, equity, inclusion, and student success. Certainly, educators at broad and open access institutions (as well as others) understand their work in the context of massive social and cultural asymmetries of resources and privilege. I am merely arguing for accelerating and deepening the sense of urgency and complexity and extending it to the entire enterprise of human learning, where "student success" is the proxy for the larger problem of "human success." Complexity, moral urgency, and a growing understanding of the entire ecosystem of learning should shape for educational developers the essence of their professional identity, intellectual perspective, and creative action.

How might a convergent and ecosystemic approach to the problem of learning shape the work of educational development and edu- 
cational transformation more broadly? As a reference point, let's look at the "principles" and "surface structures" of educational development, as identified by Felten and Chick (2018). They argue that educational development, like SoTL, is always framed with these five principles:

1. Focused on learning: All educational development aims to support faculty (including graduate and professional students) and organizational learning and, by doing that, to promote student learning.

2. Grounded in context: Educational developers carefully attend to the scholarly, disciplinary, and local contexts of their work.

3. Methodologically sound: Effective educational development methods are not "one-size fits-all" but rather are carefully tailored to the needs and goals of particular individuals, departments, or institutions.

4. Conducted in partnership: Educational development, like SoTL, is most effective when it is done with rather than to individuals.

5. Appropriately public: Just as SoTL frames teaching as "community property," effective educational development always aims toward sharing processes and products in ways that allow for peer review and adaptation in other contexts.

In a wicked problem framework, each of these principles and practices deepens and diversifies. The richness of our conceptions of learning, the complexity of our contexts, the sophistication of our methods, the plural nature of our partnerships, and the proliferation of our publics all need to both expand and harmonize in order to contribute to a Convergence approach to the problem of learning. Yet how these principles and practices evolve in a wicked framework will be shaped by the distinctive nature of learning in the contexts of education and, even more particularly, higher education. To repeat the assertion from Convergence: The Future of Health, "The Convergence Revolution does not rest on a particular scientific advance but on a new integrated approach for achieving advances [emphasis added]" (p. 17). 
With this in mind, I propose here a set of ideas for how educational development could play a crucial role in a new integrated Convergence approach.

First, a Convergence approach demands that interdisciplinary and transdisciplinary expertise be grounded in practice and practitioners. This means valuing practitioners that are diverse in role and perspective, as well as discipline. A truly convergent approach to the problem of learning and education is more than a research stance; it isa stance on the intersections of theory and practice in the increasingly complex and diverse settings where education takes place. And in this sense, a transdisciplinary approach is not just about disciplines or academic expertise, but also about functional role, identity, and perspective. Everyone-diverse faculty, staff, advisors, students-should be regarded as learners, inquirers, researchers, and agents of change.

Second, given this grounding in practice, a wicked problem stance elevates and reframes the centrality of professional and organizational learning. There is growing evidence of the impact of faculty professional development (professional learning) on student learning outcomes (Condon, et. al., 2016). There is also evidence that many of the change initiatives in the last two decades have been limited in part because of the lack of investment in professional learning. The New Learning Compact (Bass et al., 2019) argues that successful change processes require the continuous engagement of educators through professional learning and educational development at multiple scales, from individual to ecosystem. If higher education institutions and networks are complex systems, then professional learning is how these systems learn. "Complex adaptive systems grow smarter over time as they respond to specific and changing needs of their components in relationship to each other and in relationship to their environments" (Pendleton-Jullian and \& Brown, 2018, p. 175). Because the problem of learning and higher education has too often been seen as a tame and solvable problem, professional learning (including SoTL) has too often been regarded as marginal; in a wicked problem stance, professional learning is essential not only for quality and impact, but also for 
complex adaptation and therefore at the heart of all strategic approaches to sustained transformation. In order to play this role, professional learning must develop new capacities that arise from four productive tensions.

\section{Fast and Slow Change}

Just as Kahneman's (2011) work on human judgment and decisionmaking demonstrated that our minds have two systems of thoughtsfast and intuitive, slow and deliberative-every institution needs, I believe, both fast change and slow change strategies. Universities and colleges are good at slow change strategies. It is one of the reasons for their historical endurance and stability. Yet the complexity of needs and the volatility of the contemporary context make slow change strategies alone inadequate to the task. Educational developers can be pivotal agents of fast change strategies on campuses. Academic units and faculty governance structures are not built for fast change nor versed in innovative methodologies such as rapid prototyping and agile design. Educational development should be at the forefront of these fast change strategies by being thoughtful translators and integrators of human-centered design, social innovation, entrepreneurial thought, and pilot-driven approaches with theories of learning and pedagogy, intercultural theories, curriculum design, learning assessment, community building, and collective inquiry. This integrative tool set is crucial to the positive adaptation of higher education to rapidly changing conditions.

\section{Impact and Emergence}

For the first time in the history of modern higher education, we now know enough about effective instruction that we can earnestly talk about minimum standards of responsible professional practice. Several decades now of thoughtful SoTL, learning sciences research, and 
evidence-based learning design have produced an actionable body of best practices to guide curriculum transformation in a whole host of ways. The robust field of educational development has expanded and flourished around this body of work. This is what I would call designing for impact.

What is not yet really visible or valued in higher education is what Pendleton-Jullian and Brown (2018) call "designing for emergence." "Designing for emergence," they argue, is a "new tool" for adapting to a rapidly shifting and unpredictable world. If we think of the problem of learning as a complex problem, then we need the appropriate design processes for that complexity and "emergence and complexity are two sides of the same coin." They assert that "complexity arises out of emergent properties and emergence sustains complex systems. Emergent systems are complex systems that exhibit self-organizing behavior" (p. 163). To design for emergence is to value uncertainty and unpredictability. In education, while it must be enacted thoughtfully and responsibly, designing for emergence would value experimentation that led to greater adaptability of structures and practices, more flexibility and diversity in interactions, and heightened capacity for rapid organizational learning.

For all of the efficacy of the learning assessment movement, it runs the risk of having a limiting effect, bounding learning design around predictable and measurable outcomes. In a wicked problem stance, some learning design research (pedagogical and curricular) should be carried out solely for the purpose of discovering the "adjacent possible" (Kauffman, 1995). One impact of designing for emergence is that educational developers, and the larger network of innovators, would no longer think of unbundling and disruption as the "other" of traditional institutions of higher education. It should empower colleges and universities to play at innovation and transformation from inside the culture, values, and practices intrinsic to institutional higher education. 


\section{Systems and Ecosystems}

The problem of learning is both a systems problem and an ecosystem problem. On the one hand, we have to continue to understand teaching and learning in the context of what must be an increasingly aligned system of learning. This is the principal argument of Jankowski and Marshall (2017), who advocate shifting to a "learning systems paradigm," a model that embeds the "learning paradigm" that Barr and Tagg (1995) introduced more than 20 years earlier. The learning paradigm represented a transformational shift from the conventional "instructional paradigm," which focuses on content and the instructor (inputs), to the impact on the learner (outcomes). The transition from an instructional paradigm to a learning paradigm was perhaps the most captivating idea of the latter half of the 1990s. While honoring that impact, Jankowski and Marshall argue that the learning paradigm is basically a pedagogical concept, not a curricular one. They argue that what is needed is a broader systems approach that supports a "process of alignment across levels and layers of disciplinary instruction" and that shifts "from thinking about the pedagogies that produce student learning to thinking about the relationships with the organizational systems in which pedagogies are situated" (p. 43). This is what they call the learning systems paradigm.

The inquiry and implementation practices associated with this kind of alignment, coherence, and curricular rationalization is clearly part of the Convergence research model that must shape educational development. Yet the full impact of all three problems of learningunderstanding learning, scaling quality education, and the role of education in a sustainable human future-contextualizes the "learning systems" approach in a yet more open-ended inquiry into what constitutes "good education." Ultimately, education is not only a matter of mastering systems but also the interaction of learning systems in an increasingly complex ecosystem. The boundaries between the inside of higher education systems and the broader ecosystem are not only more porous but in some ways have been laid bare: whether it is an 
event that brings trauma tragedy into the classroom, reverberates with histories of systemic inequality and are deeply shaped by legacies of privilege and stratification that have become hard-wired into our assumptions about higher education. When you move to the ecosystem level, you lose certainty and predictability and you open up the idea of learning to all the complexities of human community, wellbeing, and relationships. You cannot systems engineer an ecosystem, which means you cannot fully systems-engineer education.

In Remaking College, Kirst and Stevens (2015) explore what they call an "ecological approach" to studying higher education, which is based on seeing the entire complex higher education ecosystem. They argue that an ecological approach is not just a matter of recontextualization but a necessary shift in the research paradigm that results from changes in higher education itself. The ecological approach, they argue, can "free analysts of the conceptual limitations imposed by traditional students, linear models of individual academic progression, narrow idealizations of form, and the presumption that college happens through co-presence." They argue that, on their own, "linear models of students moving through college profoundly limit our ability to think about colleges themselves as active players in the production of education" (p. 6). In breaking out of the narrow paradigm of traditional institutions and students, researchers can study higher education as an ecology.

The ecological_or ecosystemic_paradigm is well aligned with the stance of seeing the problem of learning and education as a wicked problem. "An ecological approach asks analysts," says Stevens (2015),

to conceive of higher education as comprising myriad service providers, instructional and administrative labor, funders, and regulators interacting in a messy system of educational production. These entities simultaneously cooperate and compete for scarce resources. Resources include students (of varying academic preparation and ability to pay), academic labor, tuition, government and philanthropic financial support, visibility, evaluative authority, legitimacy, and prestige. Ecological 
approaches ask us to consider how components of the ecology are interdependent. (p. 6)

Seeing the complexity and interdependency of the entire education ecosystem does decenter institutional higher education in certain ways that are potentially generative. A more ecological or ecosystemic view of education reframes the way we might think about the whole landscape of actors; supply and demand for education; the flow of resources; and the benefits, uses, waste, loss, and costs of our systems. Approaching the problem of education as a wicked problem, in an ecological paradigm, might help us think about our work in new ways. For example, how might we reframe our approach to educational development if we understood higher education institutions as one set of actors among many in the learning ecosystem and as such saw our institutions as much as consumers of students as students are consumers of education? How might we think, design, and act differently if we saw institutions engaging with human talent in ways comparable to how sustainability thinks about resources in manufacturing, where linear paradigms of "take, make, use, dispose" are transforming into circular paradigms of "reuse" and "upcycling"? What might a "circular educational paradigm" look like comparable to the "circular economy" of sustainable manufacturing and use, where the goal was to let no talent get wasted and disposed?

\section{Evidence and Imagination}

We should balance our well-placed dedication to evidence with professional competency in imagination. Higher education needs to be intrinsically and integrally imaginative (Barnett, 2013; Barnett \& Jackson, 2020). Continuously reimagining the nature, purposes, and practices of education, the shifting boundaries of learning, and the expansion of stakeholders and players in the landscape is essential to a wicked problem stance. It will almost certainly be a requirement for fully realizing the strategies above-fast and slow change, emergence 
and ecosystemic design. As Staley (2019) puts it, "The problem is not that universities are lacking in innovation, but rather that they suffer from a poverty of imagination of what that innovation might be" ( $p$. 12). Drawing on the work of Barnett (2013), Staley's book Alternative Universities is an exercise in "feasible utopias," which are meant to invoke models that are feasible but not fully realizable, grounded in the present but stretching capacities and potential in productive ways.

Imagining, debating, and playing with feasible utopias is only one of many roles that imagination might play in educational development. The larger and more salient point is that if universities cannot be the world's leaders in thinking imaginatively about their own practices then they are not living up to their own self-image as unique institutions in human society. Educational developers, and the crossfunctional roles that they play within and across institutions, should be central to the "imaginative infrastructure" (Barnett, 2013, p. 147) that will drive a truly interdisciplinary and transdisciplinary approach to the problem of learning.

\section{Coda}

Among the potential objections or critiques of my position in this article is the idea that many educational developers already think of our situation as dire, urgent, and complex. The problem, some might say, is that the right people (those with power and money) need to think that way. As I've said above, getting leaders and "the public" to recognize the wickedness of the problem of learning and higher education is a core challenge and important goal. However, I believe that a sense of urgency, and the practices attendant on a wicked problem stance, begin at home, so to speak. As the writer and performer Anna Deavere Smith once said after a performance, when asked by an audience member if she didn't sometimes feel as if she were just "preaching to the choir," "Well, I think maybe we could all use some choir practice." There is no hope of a broader public acceptance of a wicked 
problem stance unless higher education itself embraces it. Education development can play a crucial and unique role in that embrace.

In a wicked problem frame, the optimization of educational practice is not the end game. The end game should be the continuous pursuit of the existential project to help "humans get better at being human" (Bass, 2018, p. 34). That has to be the full context of professional learning and educational development. We must deepen our knowledge, integrate our perspectives and apply and reflect on our findings in ways that do not just deepen our tools, methods and principles of good practice, but also restlessly and authentically open up the questions of learning and higher education as if our human future depended on it. However daunting and intractable the problem of education was before this century, it is far more wicked now. We should respond accordingly.

\section{Biography}

Randy Bass is Vice Provost for Education and Professor of English at Georgetown University, where he leads the Designing the Future(s) initiative and the Red House incubator for curricular transformation. For 13 years he was the Founding Executive Director of Georgetown's Center for New Designs in Learning and Scholarship (CNDLS).

\section{References}

Austin Center for Design. (2019). Wicked problems: Problems worth solving. https://www.wickedproblems.com/

Barnett, R. (2013). Imagining the university. Routledge.

Barnett, R., \& Jackson, N. (Eds.). (2020). Ecologies for learning and practice: Emerging ideas, sightings, and possibilities. Routledge.

Barr, R. B. and Tagg, J. (1995). "From Teaching to Learning: A New Paradigm for Higher Education." Change. November/December, 1995, pp. 13-25.

Bass, R. (1999). The scholarship of teaching and learning: What's the problem?" Inventio, 1(1). 
Bass, R. (2018). The impact of technology on the future of human learning. Change: The Magazine of Higher Learning, 50(3-4), 34-39. https://doi.org $/ 10.1080 / 00091383.2018 .1507380$

Bass, R., Gambino, L. M., \& Eynon, B. (2019). The new learning compact: A framework for professional learning and educational change.

Baum, S., \& McPherson, M. S. (Eds.). (2019). Improving teaching: Strengthening the college learning experience. Daedalus, 148(4). https://www. amacad.org/daedalus/improving-teaching-strengthening-college-learningexperience.

Biesta, G. J. J. (2006). Beyond learning: Democratic education for a human future. Paradigm, 2006.

Biesta, G. J. J., \& Burbules, N. C. (2004). Pragmatism and educational research. Rowman \& Littlefield.

Condon, W., Iverson, E.R., Manduca, C. A., Rutz, C., \& Willett, G. (2016). Faculty development and student learning: Assessing the connections. Indiana University Press.

Convergence: The future of health. (2016). http://www.convergencerevolution.net/

Cottom, T. M. (2019, Summer). "Rethinking the context of edtech. Educause Review, 22-29. https://er.educause.edu/-/media/files/articles/2019/8/ er193103.pdf

Eberly Center. (n.d.). Handle difficult moments with respect \& sensitivity. https://www.cmu.edu/teaching/designteach/teach/classroomclimate/handledifficultmoments.html\#tragedy

Eyler, J. R. (2018). How humans learn: The science and stories behind effective college teaching. West Virginia University Press.

Felten, P., \& Chick, N. (2018). Is SoTL a signature pedagogy of educational development? To Improve the Academy, 37(1), 4-16. https://doi. org/10.1002/tia2.20077

Gibbs, G. (2013). Reflections on the changing nature of educational development. International journal of educational development, 18(1), 4-14. https://doi.org/10.1080/1360144X.2013.751691

Gomez, L. (2017, January 15). The fierce urgency of now: A reflection on Dr. Martin Luther King, Jr.'s call to action and educational equity [Blog post]. Carnegie Commons Blog. https://www.carnegiefoundation.org/blog/ the-fierce-urgency-of-now/

Jankowski, N. A., \& Marshall, D. W. (2017). Degrees that matter: Moving higher education to a earning systems paradigm. Stylus Publishing.

Kahneman, D. (2011). Thinking, fast and slow. Farrar, Straus and Giroux.

Kauffman, S. (1995). At home in the universe: The search for the laws of selforganization and complexity. Oxford University Press.

Kim, J., \& Maloney, E. (2020). Learning innovation and the future of higher education. Johns Hopkins University Press.

To Improve the Academy • Vol. 39, No. 1 • Spring 2020 
King, M. L., Jr. (1967a). Beyond Vietnam, a time to break silence [Speech]. https://kinginstitute.stanford.edu/king-papers/documents/ beyond-vietnam

King, M. L., Jr. (1967b). Where do we go from here? [Speech]. https://kinginstitute.stanford.edu/king-papers/documents/where-do-we-go-here-addressdelivered-eleventh-annual-sclc-convention

Kirst, M. W., \& Stevens, M. L. (Eds.). (2015). Remaking college: The changing ecology of higher education. Stanford University Press.

National Academy of Engineering. (2019). NAE grand challenges for engineering: Advance personalized learning. http://www.engineeringchallenges.org/challenges/learning.aspx

National Science Foundation. (2019). Convergence research at NSF. https://www.nsf.gov/od/oia/convergence/

Pendleton-Jullian, A. M., \& Brown, J. S. (2018). Design unbound: Designing for emergence in a white water world. MIT Press.

Rittel, H. W. J., \& Webber, M. M. (1973). Dilemmas in a general theory of planning. Policy Sciences, 4(2), 155-169. https://doi.org/10.1007/BF01405730

Staley, D. J. (2019). Alternative universities: Speculative design for innovation in higher education. Johns Hopkins University Press.

Stevens, M. L. (2015). Introduction: The changing ecology of U.S. higher education. In M. W. Kirst \& M. L. Stevens (Eds.), Remaking college: The changing ecology of higher education (pp. 1-15). Stanford University Press.

Watters, A. (2019, December 31). The 100 worst ed-tech debacles of the decade. http://hackeducation.com/2019/12/31/what-a-shitshow

Weiss, J. A. and Khademian, A. "What Universities Get Right -- and Wrong -About Grand Challenge Strategies." Inside Higher Education, September $3,2019$. 